Vol 1. No 2. Agustus 2017

\title{
Diversitas Arthropoda Gua di kawasan Karst Gunung Sewu, Studi gua-gua di Kabupaten Wonogiri
}

\author{
Tatag Bagus Putra Prakarsa1 ${ }^{*}$, Kurnia Ahmadin² \\ ${ }^{1}$ Prodi Biologi F.Saintek UIN Sunan Ampel Surabaya \\ ${ }^{2}$ BSG (Biospeleology Studien Gruppen) Kelompok Studi Biospeleologi, Biologi- UNY Yogyakarta \\ *Email:bagusprakarsa13@gmail.com
}

\begin{abstract}
Abstrak
Penelitian ini bertujuan untuk mengungkap keanekragaman Arthropoda di kawasan karst Gunung Sewu khususnya di wilayah kabupaten Wonogiri. Penelitian ini merupakan penelitian ekologi komunitas dengan metode Nature Snapshot Experiment (NSE). Penelitian ini dilaksanakan pada bulan Agustus 2016, bertempat di 3 gua di kawasan karst Gunung Sewu, yang masuk dalam wilayah administrasi Kabupaten Wonoggiri Jawa Tengah. Arthropoda gua yang ditemukan terdiri dari Heteropoda sp., Charon grayi, Theliphonus sp., Asamiidae ${ }^{\mathrm{F}}$, Philoscia sp.,Cambalopsidae , Geophilus sp., Scutigera sp., Tenebrionidae ${ }^{\mathrm{F}}$, Rhaphidophora dammermani, dan FormicidaeF. Habitat gua Sodong dan Potro Bunder membentuk kelompok tersendiri berdasarkan nilai indeks similaritas Jaccard. Kondisi kerusakan lingkungan gua mendasari pemilihan habitat oleh kelelawar. Sehingga dua gua yang mengelompok hanya dihuni lebih sedikit spesies dibandingkan dengan habitat gua Song Gilap.
\end{abstract}

Kata Kunci: Diversitas, Arthropoda, Gua, Karst Gunung Sewu

\section{PENDAHULUAN}

Kawasan karst Gunung sewu merupakan kawasan karst terluas di Pulau Jawa. Kawasan karst tersebut membentang di 3 kabupaten yang meliputi kabupaten Gunung Kidul DI. Yogyakarta, kabupaten Wonogiri Jawa tengah, dan kabupaten Pacitan Jawa Timur. Kawasan karst memiliki kekayaan biodiversitas di permukaan (eksokarst) dan di bawah permukaan (endokarst) atau disebut juga sebagai gua. Organisme di dalam gua dikelompokan menjadi organisme terestrial dan akuatik. Organisme terestrial dikategorikan menjadi menjadi trogloxene, troglobite, dan troglophile, organisme akuatik di kategorikan menjadi stygoxen, stygobite, dan stygophile (Culver dan White,2005; Fereira dan Horta, 2001).

Diversitasdi gua-gua Wonogiri selama ini belum banyak dkaji khususnya 
Arthropoda gua. Studi sampai saat ini masih terpusat di sebagain besar gua-gua di Gunung Kidul dan beberapa gua di Pacitan. Diperkirakan gua-gua di Wonogiri sebagai bagian Kawasan karst Gunung Sewu menyimpan banyak biodiversitas yang menarik untuk dikaji. Di samping itu, kawasan karst terus menghadapi pengrusakan yang sangat masif. Hal ini dihawatirkan banyak spesies yang terancam punah dan dimungkinkan terdapat spesies yang balum teridentifikasi punah terlebih dahulu. Penelitian ini bertujuan untuk mengetahui diversitas Arthropoda gua di kawasan karst Gunug Sewu yang masuk dalam wilayah administrasi Kabupaten Wonogiri.

\section{METODE}

Penelitian ini dilaksanakan pada bulan Juni - Agustus 2012, di 3 guadi kawasan karst Gunung Sewu, yang masuk dalam wilayah administrasi Kabupaten Wonogiri Jawa Tengah. Lokasi penelitian disajikan dalam tabel 1.

Tabel 1. Gua lokasi penelitian

\begin{tabular}{|c|c|c|}
\hline No. & Nama Gua & $\begin{array}{l}\text { Koordinat } \\
\text { (GPS) }\end{array}$ \\
\hline 1 & Song Gilap & $\begin{array}{l}\text { S 08०03'03.1" } \\
\text { E } 110^{\circ} 46^{\prime} 46.5^{\prime \prime}\end{array}$ \\
\hline 2 & Sodong & $\begin{array}{l}\text { S 08०02'25.7" } \\
\text { E } 110^{\circ} 46^{\prime} 56.3^{\prime \prime}\end{array}$ \\
\hline 3 & Potro Bunder & $\begin{array}{l}\text { S } 08^{\circ} 02^{\prime} 39.4^{\prime \prime} \\
\text { E } 110^{\circ} 46^{\prime} 48.9^{\prime \prime}\end{array}$ \\
\hline
\end{tabular}

Penelitian ini merupakan penelitian ekologi dengan jenis penelitian NaturalSnapshot Experiment (NSE). Skala spasial yang digunakan adalah skala populasi lokal dan skala temporal yang digunakan adalah skala satu generasi (Diamond, 1986).

Prosedur Penelitian ini terbagi menjadi dua tahap yaitu koleksi lapangan dan penanganan laboratorium. Koleksi Arthropoda yang relatif besar dilakukan dengan tangkap langsung, Arthropoda yang ukuran kecil disampling dengan pitfall trap. Pitfall trap menggunukan botol flacon berisi larutan atractant sekaligus pengawet yang menarik arthropoda tanah mendekat dan masuk (McEwen, 1997; Michael, 1984). Botol ini ditanam dilantai gua yang dilakukan berdasarkan zonasi gua. Di zona mulut/terang, zona remang, dan zona gelap total di tanam masing-masing 3 pitfall traps. Penyusunan pitfall dilakukan dengan modifikasi metode line transek. Penanganan laboratorium merupakan langkah lanjutan yang berupa identifikasi spesies yang dikoleksi dari lapangan. Penamaan spesies Arthropoda mengacu pada kunci identifikasi Boror et al. (1994), Ruppert et al. (2004), Weygoldt (2000), danSpelda (2015), Hubungan antar gua dianalisis menggunakan metode UPGMA (unweighted 
pairgroupmethod using arithmetic Tiga kategori tersebut meliputi troglobite. averages) (Sneath dan Sokal 1973).

trogloxene, dan troglophile. Troglobite yaitu biota gua yang hidupnya telah menetap di gua dan telah mengalami proses adaptasi dengan kondisi gua yang

Tabel 2. Arthropoda di gua-gua Wonogiri

\begin{tabular}{|c|c|c|c|c|}
\hline \multirow{2}{*}{ Spesies * } & \multicolumn{3}{|c|}{ Gua } & \multirow{2}{*}{ Kel } \\
\hline & Song Gilap & Sodong & P.Bundr & \\
\hline \multicolumn{5}{|l|}{ ArachnidaC } \\
\hline \multicolumn{5}{|l|}{ Araneae $^{0}$} \\
\hline \multirow{2}{*}{$\begin{array}{l}\text { Heteropoda sp. } \\
\text { Amblypygi }\end{array}$} & $\sqrt{ }$ & $\sqrt{ }$ & $\sqrt{ }$ & $\mathrm{Tx}$ \\
\hline & & & & \\
\hline Charon grayi & $\sqrt{ }$ & $\sqrt{ }$ & - & $\mathrm{Tl}$ \\
\hline \multicolumn{5}{|l|}{ Uropygi } \\
\hline \multirow{2}{*}{$\begin{array}{l}\text { Theliphonus sp. } \\
\text { Opiliones }\end{array}$} & $\sqrt{ }$ & - & - & $\mathrm{Tl}$ \\
\hline & & & & \\
\hline Asamiidae ${ }^{\mathrm{F}}$ & $\sqrt{ }$ & $\sqrt{ }$ & - & $\mathrm{Tl}$ \\
\hline \multicolumn{5}{|l|}{$\begin{array}{l}\text { MalacostracaC } \\
\text { Isopoda }^{\mathrm{C}}\end{array}$} \\
\hline Philoscia sp. & - & $\sqrt{ }$ & - & $\mathrm{Tl}$ \\
\hline \multicolumn{5}{|l|}{ Diplopodac $^{\mathrm{C}}$} \\
\hline Cambalopsidae ${ }^{\mathrm{F}}$ & $\sqrt{ }$ & $\sqrt{ }$ & $\sqrt{ }$ & $\mathrm{Tl}$ \\
\hline \multicolumn{5}{|l|}{ Chilopodac } \\
\hline \multicolumn{5}{|l|}{ Scutigeromorphao } \\
\hline Scutigera sp. & $\sqrt{ }$ & - & - & $\mathrm{Tl}$ \\
\hline \multicolumn{5}{|l|}{ Insectac } \\
\hline TenebrionidaeF & $\sqrt{ }$ & - & - & $\mathrm{Tl}$ \\
\hline \multicolumn{5}{|l|}{ Orthoptera ${ }^{0}$} \\
\hline $\begin{array}{l}\text { Rhaphidophora dammermani } \\
\text { Hymenoptera }^{\mathbf{0}}\end{array}$ & $\sqrt{ }$ & - & - & $\mathrm{Tl}$ \\
\hline Formicidae $^{\mathrm{F}}$ & $\sqrt{ }$ & $\sqrt{ }$ & $\sqrt{ }$ & $\mathrm{Tx}$ \\
\hline \multicolumn{5}{|c|}{$\begin{array}{ll}\text { Ket: }^{*} & : \text { Nama Spesies atau nama takson } \\
& \text { terendah yang diketahui }\end{array}$} \\
\hline $\mathrm{Tx} \quad$ : Trogloxene & & & & \\
\hline $\mathrm{Tl}$ : Troglophile & & & & \\
\hline $\mathrm{Tb}$ : Troglobite & & & & \\
\hline
\end{tabular}

\section{HASIL DAN PEMBAHASAN}

Organime terestrial penghuni gua dibedakan menjadi 3 kategori menurut adaptasi pada habitat yang ditempatinya. gelap total. Biota ini ditemukan di zona gelap total dan tidak ditemukan di habitat lain. Troglophile yaitu biota gua yang menetap di gua namun ditemukan juga di 
luar gua, belum mengalami modifikasi khusus. Trogloxene yaitu biota tamu di suatu gua. Gua ditempati secara periodik. (Culver dan White,2005). Arthropoda yang ditemukan di gua-gua Wonogiri disajikan dalam Tabel 2 .

Arthropoda di ketiga gua di kawasan karst Gunung Sewu yang masuk dalam wilayah Kabupaten Wonogiri terdiri dari 11 spesies dari 5 kelas.Arthropoda yang dijumpai di ketiga gua di Wonogiri jika dilihatdari morfologinya hanya terdiri dari kelompok trogloxene dan troglophile.

Diversitas Arthropoda tertinggi di gua Song gilap, diikuti gua Sodong, dan paling rendah gua Potro Bunder. Kondisi lingkungan gua sangat mempengaruhi diversitas Arthropoda yang ada di dalam kosistem gua, karena keberadaan organisme mengikuti naluri dan efisiensi penggunaan energi untuk memanfaatkan area mangsa yang tersedia (Tristiani et al. 2003, Campbell et al. 2007). Hal tersebut dapatdilihat darikondisi ekosistem gua Song gilap masih belum banyak terganggu dan mengalami kerusakan jika dibandingkan dengan kedua gua lainya. Gua Potro Bunder merupakan gua dengan intensitas gangguan tinggi dan ekosistem yang mengalami kerusakan terparah, jika dibandingkan dengan kedua gua lainya.
Hubungan ketiga ekosistem gua tersebut disajikan dalam bentuk dendogram berdasarkan indeks similaritas Jaccard pada gambar 1.

Berdasarkan dendogram tersebut, gua Sodong dan Potro Bunder membentuk kelompok tersendiri dengan nilai indeks similaritas Jaccard 0,5 (50\%) dan baru bersatu dengan gua Song Gilap pada nilai indeks similaritas 0,45 (45\%).

Terdapat beberapa spesies yang hanya di jumpai di satu gua saja. Theliphonus sp, Geophilus sp.,Scutigera sp.,Tenebrionidae, danRhaphidophora dammermanihanya terdapat di gua Song gilap. Spesies Philoscia sp.dari Ordo Isopoda hanya dijumpai di gua Sodong.

Arthropoda di dalam gua dibedakan menjadi kelompok predator dan kelompok perombak (Rahmadi, 2002). Kelompok predator menempati konsumen kedua hingga top predator. Kelompok perombak merupakan kelompok yang memakan material organik (guano) dan berperan sebagai konsumen pertama, karena di dalam gua tidak ada produsen, kecuali area yang masih mendapatkan cahaya matahari atau mendapatkan aliran air dari luar gua (inlet). Peran produsen sebagai penyedia materi dan energi untuk konsumenkonsumen di atasnya digantikan material-material organik, khususnya 

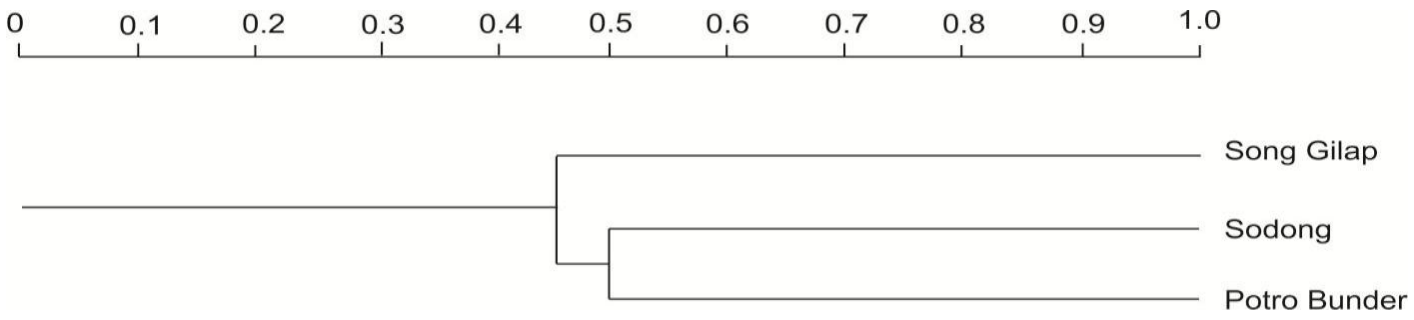

Gambar 1.Dendogram pengelompokan habitat kelelawar berdasarkan indeks similaritas Jaccard

guano (kotoran kelelawar). Kelompok perombak dalam ekosistem gua memiliki peran ganda, selain sebagai perombak material organik mereka juga berperan sebagai konsumen pertama yang langsung memanfaatkan material organik di bawah.Kelompok perombak terdiri dari Philosciidae (Isopoda), Cambalopsidae,Geophilus sp., dan R.damermani.Kelompok Predator meliputi Heteropoda sp.,C.grayi, Theliphonus sp.,Asamiidae (Opiliones), Scutigera $s p$. danFormicidae (Hymenoptera). Atrhropoda menjadi takson yang dominandan penyumbang biodiversitas terbesar di dalam gua (Vermaullen dan Whitten, 1999; Denharveng dan Bedos, 2000).

Ekosistem gua sangat rentan dengan gangguan. Sedikit saja aktivitas manusia di dalam guaakan memeberikan gangguan terhadap ekosistem di dalam gua. Gangguan terhadap eosistem gua akan langsung berimbas pada kerusakan habitat Arthropoda gua.

\section{KESIMPULAN}

Arthropoda di gua Song Gilap, Sodong, dan Potro Bunder tediri dari 11 spesies. Spesie-spesies tersebut meliputi Heteropoda sp., Charon grayi, Theliphonus sp., Asamiidae ${ }^{\mathrm{F}}$ Philoscia sp.,Cambalopsidae ${ }^{\mathrm{F}}, \quad$ Geophilus $s p$., Scutigera sp., $\quad$ Tenebrionidae ${ }^{\mathrm{F}}$, Rhaphidophora dammermani, dan Formicidae $^{\mathrm{F}}$. Habitat gua Sodong dan Potro Bunder membentuk kelompok tersendiri berdasarkan nilai indeks similaritas Jaccard. Kondisi kerusakan lingkungan gua mendasari pemilihan habitat oleh kelelawar. Sehingga dua gua yang mengelompok hanya dihuni lebih sedikit spesies dibandingkan dengan habitat gua Song Gilap.

\section{DAFTAR PUSTAKA}

Boror, DJ., Triplehorn, CA., dan NF. Johnson. 1994. Johnson. Pengenalan Pelajaran Serangga. Ed. 6. Gadjah Mada University Press, Yogyakarta

Campbell, P., Schneider, CJ.,. Zubaid, A., Adnan, AM., and TH. Kunz. 2007. 
Morphological and ecological correlates of coexistence in malaysian fruit bats (Chiroptera: Pteropodidae). Journal of Mammalogy 88(1): 105-118.

Culver, D. and W. White. 2005. Encyclopedia of caves: Elsevier Academic Press, Burlington, MA.

Denharveng, L. and A. Bedos. 2000. The Cave Fauna of East Asia: Origin, Evolution, and Ecology in Wilkens, H., Culver, D.C., and W.F. Humpreys. (ed). Ecosystem in the World vol, 30: Subterranean Ecosystem. Elsevier, Amterdam: 603-631.

Diamond, J. 1986. Overview: Laboratory Experiment, Field Experiments, and Natural Experiment. In Diamond, J. and T.J. Case (eds). Community Ecology. Harper and Row Publisher Inc, New York.

Fereira, RL. and LCS. Horta. 2001. Natural and Human Impact on Invertebrate Communities in Bazilian Caves. Rev. Brazil Biol. 61 (1): 7 - 17.

McEwen P. 1997. Sampling, handling and rearing insect, In Dent $D R \&$ Walton MP(eds) Methods in Ecological \& Agricultural Entomology. University Press, Cambridge.

Michael,P. 1984. Ecological Methods for fields \& Laboratories Investigation. McGraw-Hill Publ.Co. Ltd. New Delhi

Rahmadi, C. 2002. Keanekaragaman Fauna Gua, Gua Ngerong Tuban, Jawa Timur, Tinjauan khusus pada Arthropoda. Zoo Indonesia-Jurnal Fauna Tropica. 29: 19 - 27.

Ruppert, EE., Fox, RS., and RD. Barnes. 2004. Invertebrate Zoology, a functional evolutionary aproach. Seventh ed. Thomson Learning, Singapore.

Spelda, J. 2015. SysMyr: Systematic Myriapoda Database. didownload padaJuni 2016. www.catalogueoflife.org.

Sneath PHA, and RR., Sokal, 1973. NumericalTaxonomy. San Francisco: Freeman.

Tristiani, H., Murakami, O., and H. Watanabe. 2003. Ranging and nesting behavior of the ricefield rat Rattus argentiventer (Rodentia: Muridae) in West Java, Indonesia. Journal of Mammalogy 84(4): 12281236.

Vermaullen, J. and T. Whitten. 1999. Biodiversity and Cultural Property in the ManagementofLimestones Resources. The World Bank, Washington.

Weygold, P. 2000. Whip Spider (Chelicerata: Amblypygi) Their Biology, Morphology, and Systematics. Apollo Books, Stenstrup, Denmark. 